\title{
Estudo experimental da densidade de fluidos de perfuração base olefina e base glicerina
}

\section{Lucas S. Carmo*, Nara A. Policarpo, Nilo R. Kim, Paulo R. Ribeiro}

\section{Resumo}

Os fluidos de perfuração devem exercer pressão hidrostática no poço durante a perfuração. $O$ cálculo da pressão hidrostática depende da densidade do fluido utilizado. Portanto, o trabalho tem como objetivo o estudo da variação da densidade em função da pressão e da temperatura da olefina e fluidos base glicerina, que são utilizados como bases na formulação de fluidos de perfuração de poços de petróleo.

\section{Palavras-chave:}

Fluidos de perfuração, Olefina, Glicerina.

\section{Introdução}

Os fluidos de perfuração de poços de petróleo influenciam diretamente na performance da perfuração e na segurança durante todo o processo de extração do petróleo ${ }^{1}$. A densidade do fluido de perfuração é uma propriedade termodinâmica que deve ser conhecida em todo processo de perfuração pois o fluido tem que exercer pressão hidrostática no poço ${ }^{2}$. Nessa perspectiva, o presente trabalho tem como objetivo o estudo da densidade do metano, componente do gás natural encontrado nos reservatórios de petróleo, da olefina e da glicerina, que são fluidos usados como bases de fluidos de perfuração de poços.

\section{Resultados e Discussão}

Foi realizado o estudo da densidade dos fluidos em função da pressão e da temperatura da olefina e fluidos base glicerina - glicerina pura, solução de glicerina/salmoura 50/50 (\%vol.) (G50/50) e solução glicerina/salmoura 40/60 (G40/60). As densidades da olefina e dos fluidos à base de glicerina foram medidas em triplicatas em um densímetro (DMA 4500 Anton Paar). Para cada análise, cerca de $1 \mathrm{ml}$ de amostra era utilizada. Os resultados podem ser vistos na Tabela 1 e Figura 1.

Tabela 1. Densidades dos fluidos a 1 atm e $15,5^{\circ} \mathrm{C}$.

\begin{tabular}{|l|c|c|c|c|}
\hline Fluido & Olefina & Glicerina & G50/50 & G40/60 \\
\hline $\boldsymbol{\rho}\left(\mathbf{g} / \mathbf{c m}^{\mathbf{3}}\right)$ & 0,783 & 1,246 & 1,187 & 1,164 \\
\hline
\end{tabular}

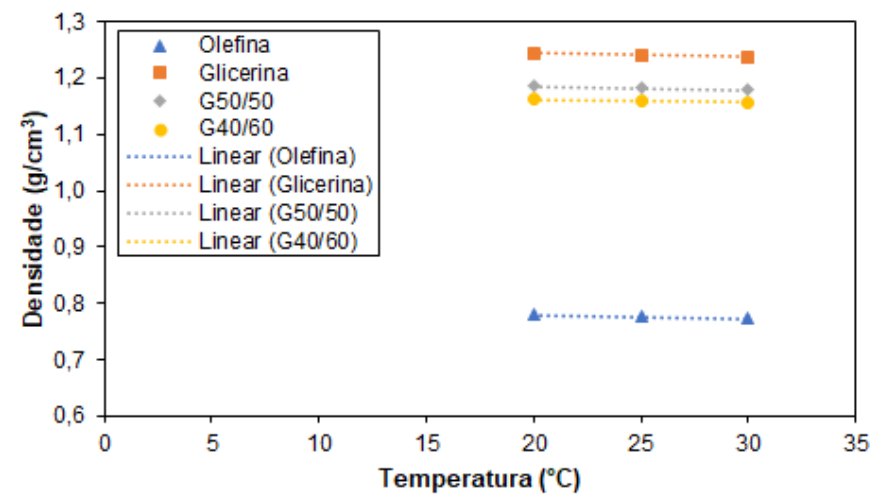

Figura 1. Densidades versus temperatura da olefina e dos fluidos base glicerina a 250 psi (17 atm).
Observa-se que a densidade da olefina é da ordem de $0,7 \mathrm{~g} / \mathrm{cm}^{3}$, valor que corresponde aos encontrados na literatura ${ }^{2,3}$. Da mesma forma, o valor da densidade da glicerina pura é cerca de $1,2 \mathrm{~g} / \mathrm{cm}^{3}$, similar ao encontrado em Corrêa et al. ${ }^{4}$ que foi de $1,24 \mathrm{~g} / \mathrm{cm}^{3}$.

A olefina é muito menos densa que os fluidos à base de glicerina, $0,7 \mathrm{~g} / \mathrm{cm}^{3}$ contra $1,2 \mathrm{~g} / \mathrm{cm}^{3}$. A densidade diminuiu com o aumento da temperatura para os quatro fluidos testados. Dos fluidos à base de glicerina, a densidade reduziu com a adição de salmoura (água e sal) na solução: $1,246 \mathrm{~g} / \mathrm{cm}^{3}$ (glicerina pura) para $1,164 \mathrm{~g} / \mathrm{cm}^{3}$ (G40/60).

A Figura 1 também mostra os ajustes lineares realizados para todos os fluidos estudados. As equações de reta ajustadas (Tabela 2) permitem o cálculo da densidade dos fluidos a 250 psi dentro do intervalo de temperaturas de 20 a $30^{\circ} \mathrm{C}$. Os ajustes realizados foram muito bons pois os $\mathrm{R}^{2}$ foram muito próximos a 1,0 .

Tabela 2. Equações ajustadas dos fluidos a 250 psi.

\begin{tabular}{|l|c|c|}
\hline Fluido & $\rho(\mathbf{T}) \mathbf{( g / \mathbf { c m } ^ { 3 } )}$ & $\mathbf{R}^{\mathbf{2}}$ \\
\hline Olefina & $\rho=-0,0007 \mathrm{~T}+0,7939$ & 0,998 \\
\hline Glicerina & $\rho=-0,0007 \mathrm{~T}+1,2586$ & 0,998 \\
\hline G50/50 & $\rho=-0,0006 \mathrm{~T}+1,1978$ & 0,996 \\
\hline G40/60 & $\rho=-0,0006 \mathrm{~T}+1,1744$ & 0,999 \\
\hline
\end{tabular}

\section{Conclusões}

Pode-se concluir que os resultados encontrados de densidade concordam com os observados na literatura, $0,7 \mathrm{~g} / \mathrm{cm}^{3}$ para a olefina e $1,2 \mathrm{~g} / \mathrm{cm}^{3}$ para a glicerina. Como esperado, as densidades dos fluidos estudados diminuem com a temperatura.

\section{Agradecimentos}

Os autores agradecem à Petrobras pelo suporte financeiro e fornecimento das amostras de fluidos e ao LMMR/CEPETRO/UNICAMP pelo uso do densímetro.

\footnotetext{
1 Thomas, J. E. (Org.). Fundamentos de Engenharia de Petróleo. Rio de Janeiro: Editora Interciência, Petrobras, 2001. 271p.

2 Demirdal, B., Cunha, J. C. Olefin-Based Synthetic-Drilling-Fluids Volumetric Behavior Under Downhole Conditions. SPE Drilling \& Completion, June, pp. 239-248, 2009.

3 Marques, D. C. Estudo das propriedades termodinâmicas de misturas de metano em olefina linear. Dissertação, FEM, Unicamp, 2016.

${ }^{4}$ Corrêa, C. C., Cruz, G. F., Vaz Jr., A. S. L., Araújo, B. S. A., Silva, A. A., Rodrigues, R. A., Lomba, R. F. T., Waldmann, A. T. A. Avaliação do Potencial Uso de Bioglicerina como Base para Formulação de Fluidos de Perfuração Aquosos para Poços de Petróleo e Gás. Química Nova, v. 40, n. 4, pp. 378-387, 2017.
} 